\title{
Categorizing COVID-19 literature from the prospective of data literacy: A systematic literature review
}

\author{
Badr Harfoush, Dakota State University, badr.harfoush@trojans.dsu.edu \\ Akhilesh Chauhan, Dakota State University, Akhilesh.Chauhan@trojans.dsu.edu \\ Cherie Noteboom, Dakota State University, cherie.noteboom@dsu.edu
}

\begin{abstract}
Healthcare generates large amounts of data that require professional skills to analyze it for decisionmaking. In the case of pandemics, generated data is used for analysis and interpretation. Healthcare professionals, governments, researchers, and the general public use the information and analysis results for awareness, alerting the public about conditions to curb the spread of diseases. Currently, the world is battling the virulent COVID-19 pandemic. Data related to the disease is streaming from around the world. This data has to be analyzed, processed, and transformed into easily consumed information by users. Different skills are needed when interacting with this data to draw inferences. This paper seeks to carry out a systematic literature review (SLR) on the COVID-19 pandemic and investigate the role of data literacy in the information systems response. The classification of literature focuses on the types of data, users, and technologies utilized in response to COVID-19.
\end{abstract}

Keywords: Data literacy, COVID-19, Coronavirus, SARS-COV-2, Pandemic, Infectious disease, \& Epidemiology.

\section{Introduction}

Today, the Internet plays a vital role in generating data from different sources across the globe. The multiple sources have enriched computational \& analysis fields such as visualization, data analytics, \& machine learning. Although, the user's skill level plays an essential role in leveraging data \& solving problems. However, limited research has analyzed the human element in understanding incredibly complex data. Similarly, there is little research about the skills people must learn to design, interpret, interact, \& critique complex data visualization \& analysis. Data literacy can be looked at by the type of user, using several classifications: health care professionals, academicians, researchers, government, \& the general public. The term data literacy broadly describes the set of abilities around using data as part of everyday thinking \& reasoning for solving real-world problems. More simply, data literacy is the ability to understand data \& effectively use it in making informed decisions. Data literacy skills \& competencies include identification, collection, organization, analysis, summarization, \& data prioritization. Data literacy is a life skill, as data interaction increasingly becomes a daily routine $\&$ an aspect of human activities where individuals are more frequently making judgments \& decisions from data use(Wolff et al., 2016). Based on this research objective, the current study poses the following questions:

What are the types of data used to address COVID-19?

What are the types of users receiving COVID-19 information?

What are the technologies for collecting \& analyzing COVID-19 data?

This study offers insights to data literacy by examining recent COVID -19 studies to identify the types of users, data, \& technologies used in the literature. The remainder of this study discusses the background \& 


\section{Issues in Information Systems}

Volume 22, Issue 4, pp. 178-192, 2021

literature review, methodology, results, discussion, limitation, conclusion \& implications for future research.

\section{Background and literature review}

Data literacy is a sub-discipline of information literacy, also known as "research data literacy" (Schneider 2013, p. 135). The analysis of information is the main focus of information literacy, statistical literacy, \& data literacy related to literature. According to (Schield, 2004), data literacy is part of statistical literacy, \& it helps in accessing, assessing, manipulating, summarizing, \& presenting data. (Calzada Prado et al. 2013, p. 126) define data literacy as "the component of information literacy that enables individuals to access, interpret, critically assess, manage, handle \& ethically use data. (Carlson et al. 2011, p. 5) explains data literacy as a way of "understanding what data means, including how to read graphs and charts appropriately, as well as draw correct conclusions from data, and recognize when data is being used in misleading or inappropriate ways." Data literacy can help the user to understand visual information during a time of pandemics. An approach to data literacy can be classified based on data type, user type, and technology type.

According to (Stedman, 1920, p. 727) a pandemic is "a disease affecting or attacking all, or a large proportion of the population of a region" and "distributed or occurring widely throughout a region, country, continent or globally" (Morens et al., 2009, p. 1018). Each pandemic has the constant variable of widespread geographic extension combined with several other standard variables like disease movement, high attack rates, explosiveness, minimal population immunity, novelty, infectiousness, contagiousness, and severity be used to define it. Currently, the COVID-19 pandemic is affecting the world. After the first identified case in late December 2019 in Wuhan, China, the contagious disease related to pneumonia, later termed as severe acute respiratory syndrome coronavirus 2 (SARS-CoV-2) or Coronavirus disease 2019 (COVID-19) (Dong et al., 2020). In Jan 2020, the first case of COVID-19 in the United States of America (USA) was reported by Johns Hopkins University, United States (Pietz et al., 2020). WHO declared COVID-19 as a global pandemic on March 11, 2020 and raised its concerns about the spread of the disease. After COVID19 became a public health emergency, information sharing about the spread of diseases became very important.

(Lee \& Jung, 2019) explains the importance of information collection and sharing for identifying the factors that ultimately impact response to controlling infectious diseases. also demonstrated the impact of misinformation spread through social media platforms and other platforms on public health. There is always a chance a person can receive rumors or misinformation when searching for information during an epidemic. It is a challenge to fill the void of lack of information during emergencies and provide evidencebased information. (Laato et al., 2020) explained the role of health organizations and social media companies in restricting unverified information on their platforms, educating their users, and sustainably suggests the consumption of information to reduce the effects of misinformation and cyberchondria problems. Johns Hopkins University, USA, successfully developed the first dashboard to track the spread of COVID-19 around the world (Dong et al., 2020; HealthITAnalytics, 2020). After this, academic researchers, independent researchers, government agencies, private and non-profit organizations around the globe started developing visual dashboards to exchange information (Johns Hopkins COVID-19 Dashboard Provides' Exhaustive Information' to Clinicians, 2020). The development of tools has created a set of verified sources of information for the public and researchers. These dashboards present information through visual representations. Understanding information through visuals depends on knowledge of the person (Bobek \& Tversky, 2016). Also, the best graphically presented information is easy to understand and it hides the complexity of data beneath it (Tufte, 1985). 


\section{Issues in Information Systems}

Volume 22, Issue 4, pp. 178-192, 2021

Information Systems play an essential role in understanding COVID-19 information available on different platforms in different sectors. The available technologies are helping users to understand the vast amount of data with dashboards. Dashboards also provide a way for users to interact with the data. The visual representations on dashboards help to deliver critical information in a timely and accurate manner. The information available on these dashboards includes demographics, location, report date, travel history, and exposure source, collected from government health authorities and news media sources (Berry et al., 2020). Some online tracking tools provide COVID-19 tracking information on the county, state, and national levels. However, studies have shown tracking COVID-19 at city levels is critical to stop the spread of COVID-19 outbreaks (Wissel et al., 2020). In pandemic response, it is crucial to provide an effective Healthcare response. Standard data sharing and visualization methods are needed and it should focus on IS researchers to develop global data sharing standards (Modjarrad et al., 2016). Lack of data sharing standards can create difficulty in sharing information and delay public health response efforts.

The ongoing dramatic change led to the advent of easy access to high bandwidth networks, the robust and ever-growing suites of advanced computation and informational data visualization tools and techniques that makes data literacy necessary for everyone (Sapp Nelson et al., 2011). Data literacy provides the opportunity for evolution for data analysts, researchers, and people across all spectrums. However, data literacy should extend to data management and data interaction either in its raw form or in its processed or analyzed state (Federer et al., 2016). Furthermore, data literacy should include searching, collecting, and retrieving data; organizing, managing, and tracking datasets, data description documentation, and data manipulation (Adamick et al., 2012). Due to advancements in technology, data literacy should also entail using and interacting with the available data analysis, mining, and representation tools and techniques such as big data, data mining, data analytics, and others (Wolff et al., 2016).

Epidemiological data can help in decision making, resource allocation and to understand spread of diseases in population. During pandemic data is collected, shared and published with the aim to help in the emergency preparedness (Fairchild et al., 2018). Data literacy is critical because of the vast amount of information available widely. Understanding published data is a key because of challenges like different interface, data format, and data reporting methods. One will not become educated just by being exposed to a large amount of knowledge; they must learn how to use it effectively (DeWalt et al., 2004). Health literacy is interpreted as the capability to handle words and numbers in a health context, but it has recently expanded to include the simultaneous use of a more complex and interrelated set of skills, such as reading and acting on documented health data, conversing necessities to

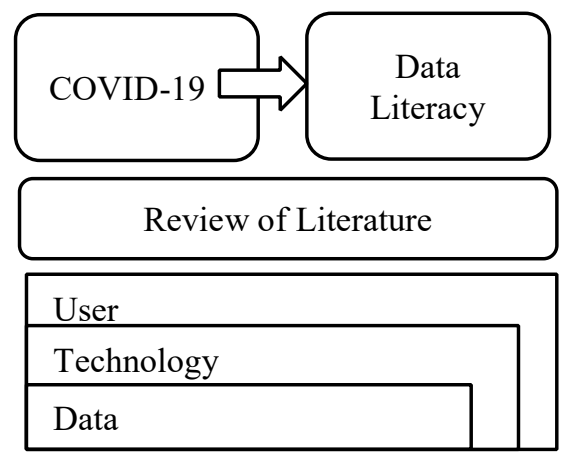

Figure 1: Conceptual Framework

health professionals, and understanding health guidelines(Ranaweera, 2008; Sørensen et al., 2012).

\section{Methodology}

This work uses (Kitchenham \& Charters, 2007) approach for literature review to investigate data literacy in relation to COVID-19. This work employs articles from 2019 to 2021, the relevant COVID-19 time frame. The articles were collected from different research databases that contain peer-reviewed journals, and conference papers: including ACM Digital Library, EBSCO Host, IEEE Xplore, PubMed, Science Direct, and Web of Science. Data literacy, COVID-19, Coronavirus, SARS-COV-2, pandemic, Infectious 


\section{Issues in Information Systems}

Volume 22, Issue 4, pp. 178-192, 2021

disease, and epidemiology are used as keywords for different database searches. A total of 492 articles were obtained using search keywords and keeping publication year between 2019 to 2021, from ACM Digital Library, EBSCO Host, IEEE Xplore, PubMed, Science Direct, and Web of Science databases in the English language. This work focuses on understanding how data literacy aids users in different domains to understand its relationship to epidemiology, pandemics, and COVID-19. The review analyses extend to the use of analytics, information systems, artificial intelligence, and other technologies for improving data literacy. The search selects articles related to COVID-19, which have information concerning users, data, or technologies. This study used title, abstract and full paper review for screening. During the abstract screening, all the authors did their screening and compared the results for the final screening.

In the initial observation, five articles showed up in multiple databases. After removing duplicates, 487 records were obtained. In the next step, title and abstract screening are completed, and 121 records were obtained. The abstracts were reviewed for relevance during screening. If the abstract contained information on data literacy for COVID-19, then articles were downloaded for in-depth review. Articles are not included if they had no focus on COVID-19. A database was created that contained relevant information on each article which include: study objective, methodology, data type, user type, technology/artifact, year of publication, and research questions. The specific search parameters helped ensure that almost all articles targeted for in-depth reading, via the abstract, were included in this review.

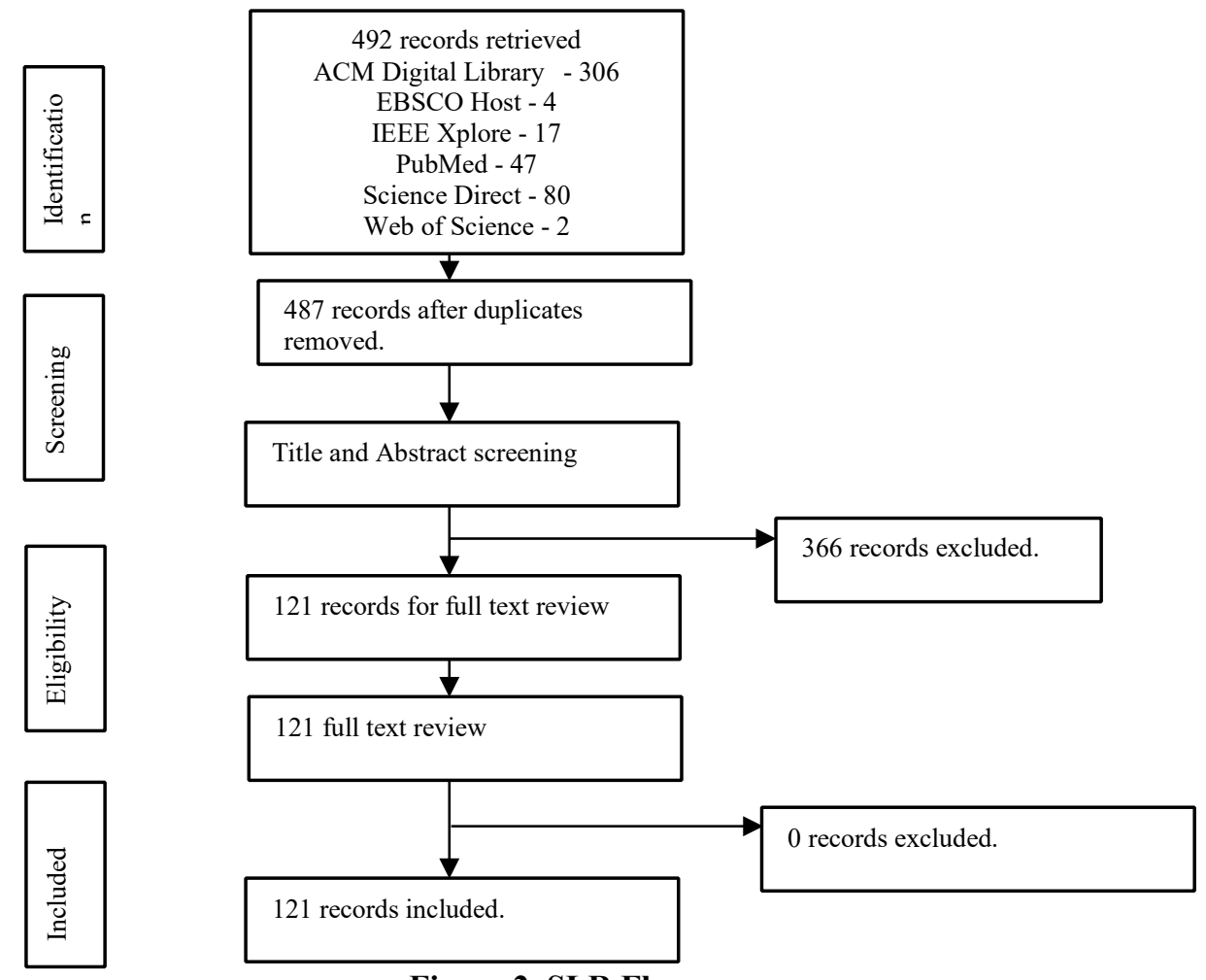

Figure 2. SLR Flow

Using the methodology, the authors were able to collect multiple papers from the different online databases. The search process followed a strict procedure as outlined by (Kitchenham \& Charters, 2007). The search included the use of keywords in the title and abstract screening and a full paper review for the eligibility of the papers. A total of 492 articles were found of which 5 were rejected on a duplication basis, and 121 of the remaining passed the review process after the title and abstract screening and full paper review. 


\section{Research questions}

The findings from this analysis are interpreted in relation to our research questions:

1. What are the types of data used to address COVID-19?

2. What are the types of users receiving COVID-19 information?

3. What are the technologies for collecting and analyzing COVID-19 data?

\section{Results}

The narrowness of the scope allowed for a tight analysis of the emerging topic of data literacy in a time of pandemics. The review filtered the paper in terms of repetition or duplication, title and abstract, and their eligibility as worthy papers for the review. For the abstract and title screening, the papers included had to contain the keywords in the title and abstract. In the full paper review, the articles had to discourse on COVID-19 data.

In table 1, different categories based on data, user, and technology are obtained and categorized in general categories. The last column of Table 1 shows the different types of users, data, and technologies that use data literacy to deal with COVID-19.

\begin{tabular}{|c|c|c|}
\hline Domain & Category & Count \\
\hline Data & $\begin{array}{l}\text { - } \text { Healthcare/Medical data } \\
\text { - } \quad \text { Survey data } \\
\text { - } \text { Opontact tracing data } \\
\text { - } \text { Fake newsets data } \\
\text { - Social/News media data } \\
\text { - Others }\end{array}$ & $\begin{array}{ll} & 59 \\
- & 16 \\
: & 8 \\
: & 20 \\
: & 1 \\
- & 4 \\
- & 13 \\
\end{array}$ \\
\hline User & $\begin{array}{ll}\text { - } & \text { Healthcare, } \\
\text { - } & \text { Public Government } \\
\text { - } & \text { Researchers } \\
\text { - } & \text { Others }\end{array}$ & $\begin{array}{ll}- & 65 \\
- & 3 \\
- & 9 \\
- & 31 \\
- & 13 \\
\end{array}$ \\
\hline Technology & $\begin{array}{ll}- & \text { Lab experiment/observation } \\
- & \text { AI/ML/DL/DM } \\
\text { - } & \text { Analytics } \\
\text { - } & \text { Tools, platforms, Mobile and web app } \\
\end{array}$ & $\begin{array}{ll}\bullet & 55 \\
: & 10 \\
: & 31 \\
: & 16 \\
- & 9 \\
\end{array}$ \\
\hline
\end{tabular}

Table 1: Paper Categorization

\section{Paper distribution analysis}

In responding to question 1; Figure 3 indicates that from a data type perspective, In terms of distribution, $62(51.2 \%)$ of the articles addresses Healthcare and medical data, $22(18.2 \%)$ address open datasets, 16 $(13.2 \%)$ address survey data, $8(6.6 \%)$ focus on contact tracing data, $1(0.8 \%)$ target the fake new data, 4 $(3.3 \%)$ focus on social/new media data, and $8(6.6 \%)$ address other types of data.

In relationship to question 2 Figure 3 indicates that the distribution of the articles shows that the health care professionals are the majority of the targeted user types, with 65 articles (representing 53.7\%) targeting the health care professionals. 31 or $25.6 \%$ of the articles target researchers, $9(7.4 \%)$ of the articles target the government, $3(2.5 \%)$ of them target the general public, and $13(10.7 \%)$ of the articles target the other types of data users. 


\section{Issues in Information Systems}

Volume 22, Issue 4, pp. 178-192, 2021
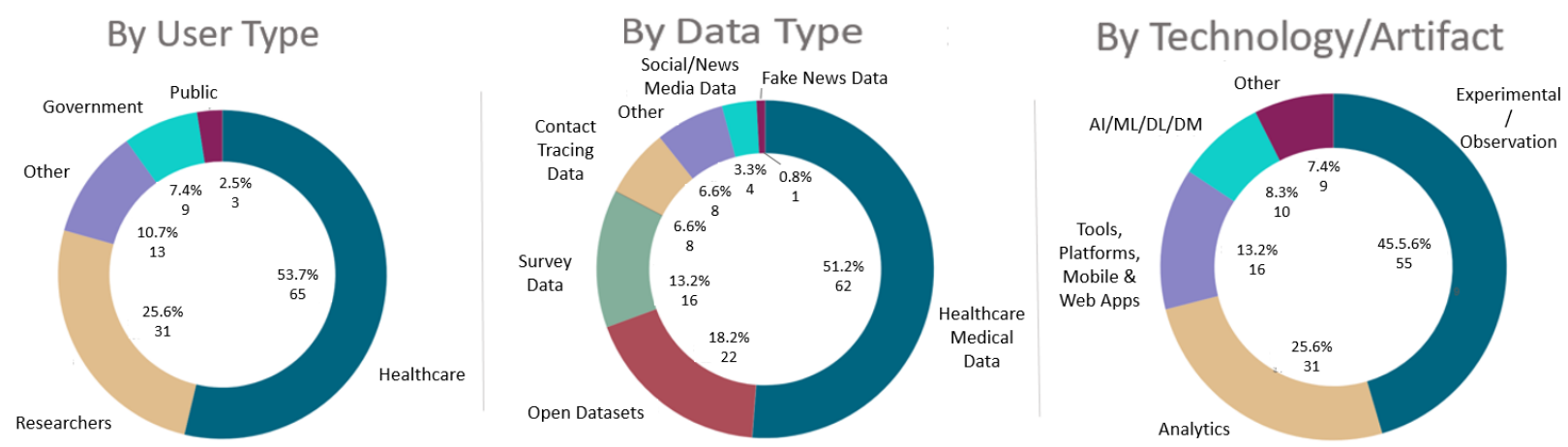

Figure 2: Distribution of papers

Figure 3. Papers Distribution

In answering question 3, Figure 3 indicates that from a technology or artifact point of view; 45.5\% (55) articles focused on the experiment or observation data, 25.6\% (31) articles target analytical data, 13.2\% (16) articles focused on data related to tools, platforms, mobile and web applications, 8.3\% (10) of articles focus on Artificial Intelligence, Machine Learning, Data Literacy and Data Management (AI/ML/DL/MD), and $7.4 \%$ (9) articles focus on other data types.

In combining user types and data types, as shown in figure 4, the distribution of the articles shows that no papers are focusing on the government and public user types based on the contact tracing data. Based on fake news, the articles found only target health care professionals. Based on Healthcare and medical data, the articles focus on all the user types except the general public. Based on open datasets, the articles focus on all the user types except the government. Based on other artifacts, the articles address only the government and other users. Concerning survey data, all the user types are targeted except the public user type. In relation to social/news media, the articles focus on the Healthcare, researchers, and other user types of categories.

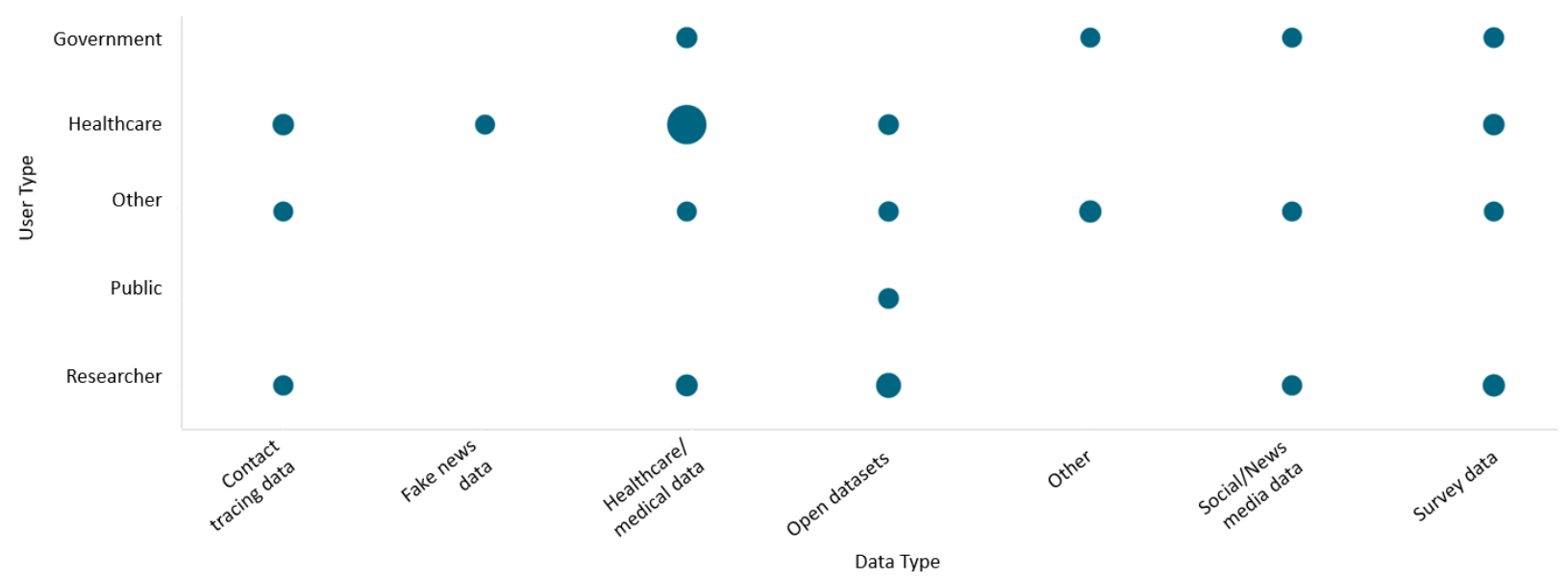

Figure 4. Analysis by User Types and Data Types

While combining the data type and the technology or artifact as shown in figure 5, the articles' distribution shows no articles that address experiment/observation and other technology types related to contact tracing data type. Based on fake news, the articles found only target the other technology types, and based on Healthcare and medical data; the articles focus on all the technology types. The articles focus on all the technology types except the AI/ML/DL/MD and tools, platforms, mobile, and web applications categories based on open datasets data types. The articles address only the analytics, tools, platforms, mobile and web 


\section{Issues in Information Systems}

Volume 22, Issue 4, pp. 178-192, 2021

applications, and other types of data types based on other data types. All the data types are targeted except the $\mathrm{AI} / \mathrm{ML} / \mathrm{DL} / \mathrm{MD}$ and other data types in relation to survey data. In relation to social/news media data type, the articles focus on the tools, platforms, mobile and web applications, and analytics categories.

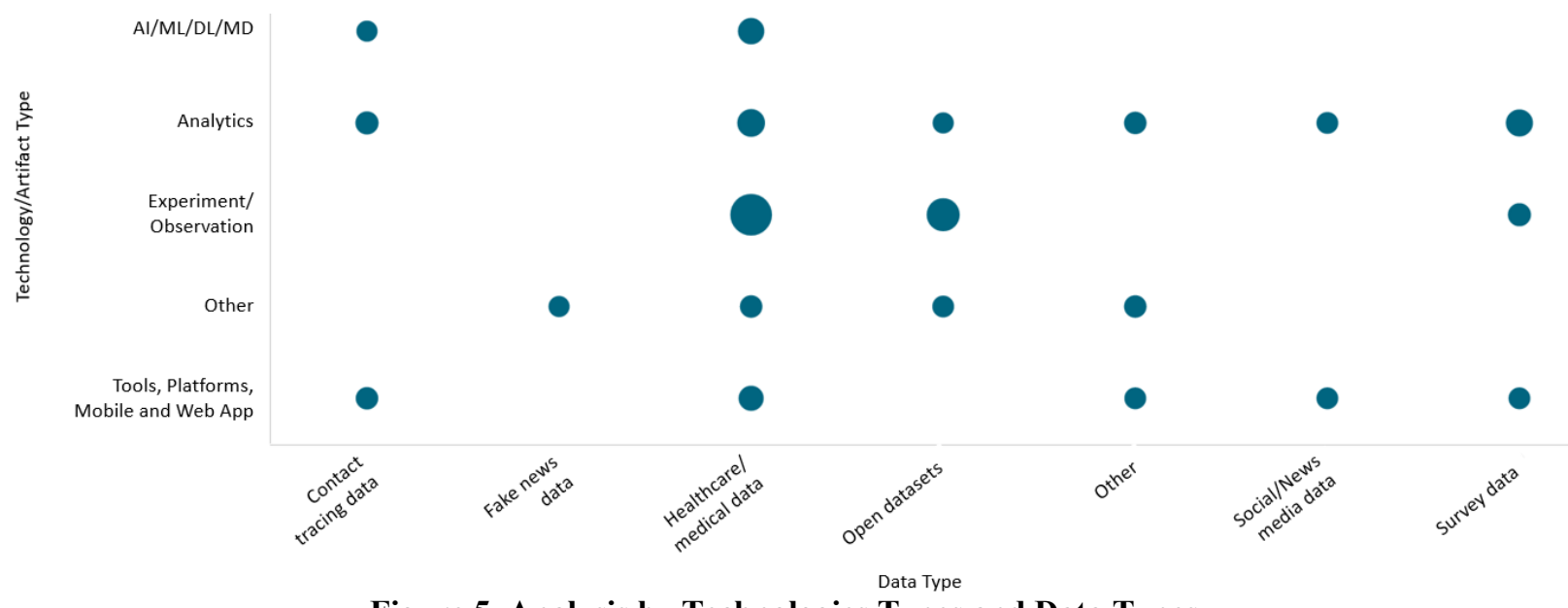

Figure 5. Analysis by Technologies Types and Data Types

In combination with the user type and the technology or artifact shown in figure 6, the articles' distribution shows that no articles target the government, public, and other user categories based on $\mathrm{AI} / \mathrm{ML} / \mathrm{DL} / \mathrm{MD}$. Based on analytics, the articles found, target all user types except the public, and the basis of experiment/observation data, the articles focus on Healthcare, researcher, and public user types. Based on other artifacts/technology, the articles focus on all the government, Healthcare, and other user type categories. The articles found focus on researchers, Healthcare, and other data user categories based on tools, platforms, mobile, and web applications.

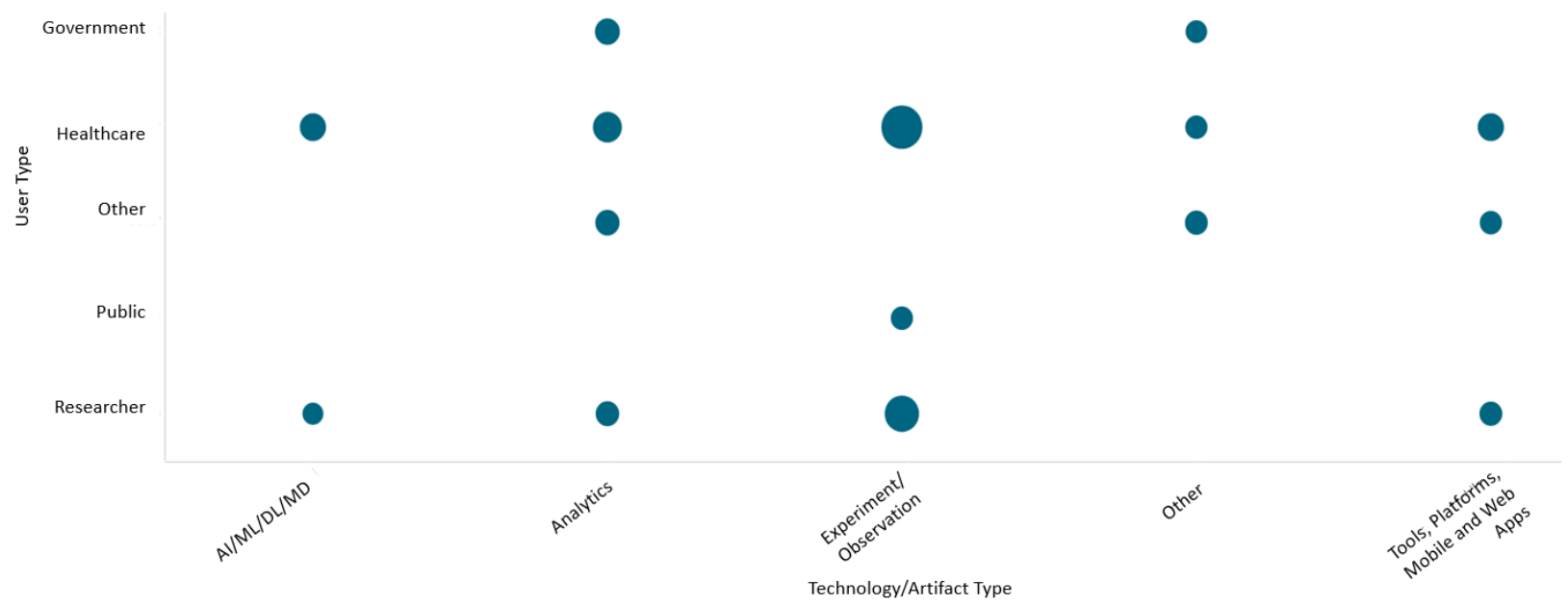

Figure 6. Analysis by User Types and Technologies Types

\section{Discussion}

For the sake of proper justification, it is important to refer back to the goal of this review. The review aimed at investigating the role played by data literacy in information system-oriented response to the COVID-19 


\section{Issues in Information Systems}

Volume 22, Issue 4, pp. 178-192, 2021

pandemic. Based on the review findings, it is evident that data literacy plays a critical role in the frontline response to the COVID-19 pandemic. From the research findings, data literacy in COVID-19 data can be viewed in lenses of data type, user types, and artifacts or technologies used in the presentation, visualization, and analysis of the data. The user types revealed in COVID-19 data include the Healthcare professionals, researchers, the government, and the public types mainly. For the data types, Healthcare/medical data, survey data, contact tracing data, open datasets, fake news data, and social/News media data types of data are evident. The artifacts or technologies evident in the COVID-19 data include lab experiment/observation, $\mathrm{AI} / \mathrm{ML} / \mathrm{DL} / \mathrm{DM}$, analytics, experiment/observation, and tools, platforms mobile, and web apps are the main types. The role played by data literacy in the response can be discussed in the following categories as outlined in the appendix table - table 2.

1. Data Type:In answering question 1, the findings from the review show that medical and Healthcare data is the most targeted data type in data literacy in response to COVID-19. Indeed COVID-19 is a public health crisis, and the larger portion of data dealt with in response to the pandemic is related to the health or medical industry. Linking the data types with the user types, it is evident that all data types are a target in research on data literacy in COVID-19 except the general public. This observation emphasizes the need for the different user types to develop skills in the interaction with all types of data types related to COVID-19. According to (Pietz et al., 2020), there is great importance for different user types, including the health care professional, government, researchers, and the public, to have a clear understanding of COVID-19 data for a compressive response to the COVID-19 pandemic. Understanding the COVID-19 data by the different user types is very important for a multi-disciplinary approach to the COVID-19 pandemic. The relationship between data types and the artifact/technology shows that it is very important for Healthcare/medical professionals and researchers to have skills in interacting and using different technologies and artifacts in analyzing and interpreting COVID-19 data.

2. User Type: In responding to question 2, Healthcare/medical professionals are the main targets when it comes to data literacy in the COVID-19 response. The Healthcare/medical professional are in the frontline when it comes to fighting COVID-19. The review findings emphasize the need for these professionals to have a high understanding of the analysis and interpretation of the COVID-19 related data. High data literacy levels amongst these professionals are essential in helping in contact tracing, understanding medical and Healthcare data, addressing fake news, carrying and interpreting surveys, and interacting with the COVID-19 data. There is also a great emphasis on the need for Healthcare/medical professionals to have skills in interacting and using the various data analysis tools. The main focus is on the use of technology on experimental and observational data, and the use of applications in Healthcare. Other than these professionals, the results bring forth the importance of data literacy for the rest of the user types in interacting with the different data types, and in using, and interacting with the different artifacts/technology (Laato et al., 2020).

3. Technology/Artifact: In satisfying question 3, the findings of this research show that technologies and artifacts related to experimental and observational analysis and analytics are the leading technologies/artifacts in the COVID-19 data literacy research. This brings forth the nature of the COVID19 as still as an experimental/observational topic whose data is still being collected and analyzed. While relating the technologies/artifacts to data type, a unique observation shows there are experimental/observational technologies tailored to contact tracing data type. This shows that the technologies and artifacts meant for contact tracing have already passed the experimental and analysis stage, and are already in the application phase. There is also a significant dedication of the artifacts/technologies to Healthcare/medical data type, which implies that most of the technologies are directed towards responding to COVID-19 as a health crisis. Furthermore, while relating the technology/artifact to the user type, there is a significant dedication of technologies/artifacts towards the medical/health care 


\section{Issues in Information Systems}

Volume 22, Issue 4, pp. 178-192, 2021

professionals. For instance,(Wissel et al., 2020) place great emphasis on the need for medical practitioners to have skills in interacting with such technologies and artifacts as dashboards. This again emphasizes the need for data literacy amongst these professionals as the frontline soldiers in the fight against COVID-19.

\section{Limitations}

COVID-19 is still a relatively new area of research. The timing of the pandemic limits the number of available articles, particularly with COVID-19 as a subject matter that was analyzed to provide conclusions. This SLR focused on literature from the COVID-19 pandemic and may have limitations due to the number of published articles at the time of review. Another limitation is the targeted databases were academic databases. A further limitation is that systematic literature reviews are vulnerable to classification errors.

\section{Conclusion and future research}

In the light of findings made in this study, it is evident that data literacy is vital for researchers, scientists, government authorities, and the general public in any given specialty. The findings of this review show that there is great importance for these users to understand the different data types and the different technologies, and artifacts used with data in relation to COVID-19 data. The different data types found show that this review includes Healthcare and medical data, open datasets, survey data, contact tracing data, fake news, social/news media data, and other types of data. The technologies and artifacts identified in the review involve lab experiment/observation, AI/ML/DL/DM, analytics, tools platforms, Mobile, and web app, and others. The novelty of COVID-19 is the main limitation in this research and it presents a significant research gap in terms of the exploration of COVID-19 from all the identified user types, data types, and artifacts/technologies. The findings of this review, therefore, call for researchers to first put much more effort into exploring COVID-19 from all angles, including all the user types, data types, and artifacts/technologies. There is a need to explore further how the different user types understand and interact with different data types and how they utilize different artifacts and technologies identified with epidemiology data. The research has to be diversified and involves multiple user types and data types, and it has to focus on the application of such technologies/artifacts such as Big Data, Data Visualization, Machine Learning, AI, and others. In this, it will be possible to evaluate and assess the data literacy levels in epidemiology data.

\section{References}

Adamick, J., Reznik-Zellen, R., \& Sheridan, M. (2012). Data Management Training for Graduate Students at a Large Research University. Journal of EScience Librarianship, 1, 180-188. https://doi.org/10.7191/jeslib.2012.1022

Berry, I., Soucy, J.-P. R., Tuite, A., \& Fisman, D. (2020). Open access epidemiologic data and an interactive dashboard to monitor the COVID-19 outbreak in Canada. CMAJ, 192(15), E420E420. https://doi.org/10.1503/cmaj. 75262

Bobek, E., \& Tversky, B. (2016). Creating visual explanations improves learning. Cognitive Research: Principles and Implications, 1. https://doi.org/10.1186/s41235-016-0031-6

Calzada Prado, F. J., \& Marzal García-Quismondo, M. Á. (2013). Incorporating Data Literacy into Information Literacy Programs: Core Competencies and Contents. https://doi.org/10.1515/libri2013-0010 


\section{Issues in Information Systems}

Volume 22, Issue 4, pp. 178-192, 2021

Carlson, J., Fosmire, M., Miller, C. C., \& Nelson, M. S. (2011). Determining Data Information Literacy Needs: A Study of Students and Research Faculty. Portal: Libraries and the Academy, 11(2), 629-657. https://doi.org/10.1353/pla.2011.0022

DeWalt, D. A., Berkman, N. D., Sheridan, S., Lohr, K. N., \& Pignone, M. P. (2004). Literacy and health outcomes. Journal of General Internal Medicine, 19(12), 1228-1239. https://doi.org/10.1111/j.1525-1497.2004.40153.x

Dong, E., Du, H., \& Gardner, L. (2020). An interactive web-based dashboard to track COVID-19 in real time. The Lancet. Infectious Diseases, 20(5), 533-534. https://doi.org/10.1016/S14733099(20)30120-1

Fairchild, G., Tasseff, B., Khalsa, H., Generous, N., Daughton, A. R., Velappan, N., Priedhorsky, R., \& Deshpande, A. (2018). Epidemiological Data Challenges: Planning for a More Robust Future Through Data Standards. Frontiers in Public Health, 6, 336. https://doi.org/10.3389/fpubh.2018.00336

Federer, L. M., Lu, Y.-L., \& Joubert, D. J. (2016). Data literacy training needs of biomedical researchers. Journal of the Medical Library Association: JMLA, 104(1), 52-57. https://doi.org/10.3163/15365050.104.1.008

HealthITAnalytics. (2020, March 11). Johns Hopkins Develops Real-Time Data Dashboard to Track Coronavirus. HealthITAnalytics. https://healthitanalytics.com/news/johns-hopkins-develops-realtime-data-dashboard-to-track-coronavirus

Johns Hopkins COVID-19 dashboard provides 'exhaustive information' to clinicians. (2020). https://www.healio.com/news/infectious-disease/20201102/johns-hopkins-covid19-dashboardprovides-exhaustive-information-to-clinicians

Kitchenham, B., \& Charters, S. (2007). Guidelines for performing Systematic Literature Reviews in Software Engineering.

Laato, S., Islam, A. K. M. N., Islam, M. N., \& Whelan, E. (2020). What drives unverified information sharing and cyberchondria during the COVID-19 pandemic? European Journal of Information Systems, 29(3), 288-305. https://doi.org/10.1080/0960085X.2020.1770632

Lee, K.-M., \& Jung, K. (2019). Factors Influencing the Response to Infectious Diseases: Focusing on the Case of SARS and MERS in South Korea. International Journal of Environmental Research and Public Health, 16(8), 1432. https://doi.org/10.3390/ijerph16081432

Modjarrad, K., Moorthy, V. S., Millett, P., Gsell, P.-S., Roth, C., \& Kieny, M.-P. (2016). Developing Global Norms for Sharing Data and Results during Public Health Emergencies. PLOS Medicine, 13(1), e1001935. https://doi.org/10.1371/journal.pmed.1001935

Morens, D. M., Folkers, G. K., \& Fauci, A. S. (2009). What Is a Pandemic? The Journal of Infectious Diseases, 200(7), 1018-1021. https://doi.org/10.1086/644537

Pietz, J., McCoy, S., \& Wilck, J. H. (2020). Chasing John Snow: Data analytics in the COVID-19 era. European Journal of Information Systems, 29(4), 388-404. https://doi.org/10.1080/0960085X.2020.1793698

Ranaweera, P. (2008). Importance of Information Literacy skills for an Information Literate society. http://eprints.rclis.org/11956/

Sapp Nelson, M., Carlson, J., Fosmire, M., \& Miller, C. (2011). Determining Data Information Literacy Needs: A Study of Students and Research Faculty. Portal-Libraries and The Academy PORTAL-LIBR ACAD, 11, 629-657. https://doi.org/10.1353/pla.2011.0022 


\section{Issues in Information Systems}

Volume 22, Issue 4, pp. 178-192, 2021

Schield, M. (2004). Information Literacy, Statistical Literacy and Data Literacy.

Sørensen, K., Van den Broucke, S., Fullam, J., Doyle, G., Pelikan, J., Slonska, Z., Brand, H., \& (HLSEU) Consortium Health Literacy Project European. (2012). Health literacy and public health: A systematic review and integration of definitions and models. BMC Public Health, 12(1), 80. https://doi.org/10.1186/1471-2458-12-80

Stedman, T. (1920). Stedman's medical dictionary. Dalcassian publishing company.

Tufte, E. R. (1985). THE VISUAL DISPLAY OF QUANTITATIVE INFORMATION. The Journal for Healthcare Quality (JHQ), 7(3), 15.

Wissel, B. D., Van Camp, P. J., Kouril, M., Weis, C., Glauser, T. A., White, P. S., Kohane, I. S., \& Dexheimer, J. W. (2020). An interactive online dashboard for tracking COVID-19 in U.S. counties, cities, and states in real time. Journal of the American Medical Informatics Association: JAMIA, 27(7), 1121-1125. https://doi.org/10.1093/jamia/ocaa071

Wolff, A., Gooch, D., Montaner, J. J. C., Rashid, U., \& Kortuem, G. (2016). Creating an Understanding of Data Literacy for a Data-driven Society. J. Community Informatics. https://doi.org/10.15353/joci.v12i3.3275

\section{Appendix - Table 2. Summary of selected studies}

\begin{tabular}{|c|c|c|c|}
\hline Title & Data Type & Technology Type & User Type \\
\hline $\begin{array}{l}\text { [Thoughts and suggestions on arrangement, analysis and summary of } \\
\text { medical data during COVID-19 epidemic]. }\end{array}$ & Healthcare/Medical data & & Healthcare \\
\hline A Comparison of Geographical Propagation Visualizations & Social/News media data & Analytics & \\
\hline $\begin{array}{l}\text { A discursive paper on the importance of health literacy among foreign } \\
\text { domestic workers during outbreaks of communicable diseases. }\end{array}$ & Fake news data & & Healthcare \\
\hline $\begin{array}{l}\text { A Note on Blind Contact Tracing at Scale with Applications to the } \\
\text { COVID-19 Pandemic }\end{array}$ & Contact tracing data & $\begin{array}{l}\text { Tools, platforms, } \\
\text { Mobile and web app }\end{array}$ & Healthcare \\
\hline $\begin{array}{l}\text { A Novel Spatio-Temporal Interpolation Algorithm and Its Application } \\
\text { to the COVID-19 Pandemic }\end{array}$ & Healthcare/Medical data & Analytics & Healthcare \\
\hline $\begin{array}{l}\text { A Spatio-GraphNet Model for Real-Time Contact Tracing of COVID- } \\
19 \text { Infection in Resource Limited Settings }\end{array}$ & Contact tracing data & Analytics & Healthcare \\
\hline A Study of the COVID-19 Impacts on the Canadian Population & Contact tracing data & Analytics & Researchers \\
\hline $\begin{array}{l}\text { Adaptive Bayesian Learning and Forecasting of Epidemic } \\
\text { Evolution-Data Analysis of the COVID-19 Outbreak }\end{array}$ & Healthcare/Medical data & Analytics & Government \\
\hline An Interactive Simulator for COVID-19 Trend Analysis & Healthcare/Medical data & $\mathrm{AI} / \mathrm{ML} / \mathrm{DL} / \mathrm{DM}$ & Healthcare \\
\hline $\begin{array}{l}\text { Are People With Chronic Diseases Satisfied With the Online Health } \\
\text { Information Related to COVID-19 During the Pandemic? }\end{array}$ & Survey data & Analytics & Government \\
\hline $\begin{array}{l}\text { Assessing Telemedicine Unreadiness Among Older Adults in the } \\
\text { United States During the COVID-19 Pandemic. }\end{array}$ & Open datasets & Analytics & Healthcare \\
\hline $\begin{array}{l}\text { Be Aware of the Hot Zone: A Warning System of Hazard Area } \\
\text { Prediction to Intervene Novel Coronavirus COVID-19 Outbreak }\end{array}$ & Healthcare/Medical data & Analytics & Government \\
\hline $\begin{array}{l}\text { Bias in Conversational Search: The Double-Edged Sword of the } \\
\text { Personalized Knowledge Graph }\end{array}$ & & Analytics & \\
\hline $\begin{array}{l}\text { Characterizing the Spread of COVID-19 from Human Mobility } \\
\text { Patterns and SocioDemographic Indicators }\end{array}$ & Contact tracing data & Analytics & Healthcare \\
\hline $\begin{array}{l}\text { Cola-GNN: Cross-Location Attention Based Graph Neural Networks } \\
\text { for Long-Term ILI Prediction }\end{array}$ & Healthcare/Medical data & Analytics & Healthcare \\
\hline Computational Intelligence Techniques for Combating COVID-19 & Survey data & Analytics & Healthcare \\
\hline
\end{tabular}




\title{
Issues in Information Systems
}

\author{
Volume 22, Issue 4, pp. 178-192, 2021
}

\begin{tabular}{|c|c|c|c|}
\hline $\begin{array}{l}\text { Concept Driven Search and Visualization System for Exploring } \\
\text { Scientific Repositories }\end{array}$ & Survey data & $\begin{array}{l}\text { Tools, platforms, } \\
\text { Mobile and web app }\end{array}$ & Healthcare \\
\hline $\begin{array}{l}\text { Coronavirus-Related Health Literacy: A Cross-Sectional Study in } \\
\text { Adults during the COVID-19 Infodemic in Germany. }\end{array}$ & Healthcare/Medical data & & Government \\
\hline COVID-19 and the Unfinished Agenda of VISION 2020 & Open datasets & & \\
\hline COVID-19 Joint Pandemic Modeling and Analysis Platform & Healthcare/Medical data & Analytics & Healthcare \\
\hline COVID-19 Kaggle Literature Organization & Healthcare/Medical data & Analytics & Healthcare \\
\hline $\begin{array}{l}\text { COVID-19 knowledge prevents biologics discontinuation: Data from } \\
\text { an Italian multicenter survey during RED-ZONE declaration }\end{array}$ & Healthcare/Medical data & Analytics & Healthcare \\
\hline $\begin{array}{l}\text { COVIZ: A System for Visual Formation and Exploration of Patient } \\
\text { Cohorts }\end{array}$ & & Analytics & \\
\hline $\begin{array}{l}\text { Data-Driven Simulation and Optimization for COVID-19 Exit } \\
\text { Strategies }\end{array}$ & & Analytics & \\
\hline $\begin{array}{l}\text { Demystifying the varying case fatality rates (CFR) of COVID-19 in } \\
\text { India: Lessons learned and future directions. }\end{array}$ & Healthcare/Medical data & Analytics & \\
\hline $\begin{array}{l}\text { Developing a Mobile App (iGAM) to Promote Gingival Health by } \\
\text { Professional Monitoring of Dental Selfies: User-Centered Design } \\
\text { Approach. }\end{array}$ & Survey data & Analytics & Healthcare \\
\hline $\begin{array}{l}\text { Digital tools against COVID-19: taxonomy, ethical challenges, and } \\
\text { navigation aid }\end{array}$ & & & Government \\
\hline $\begin{array}{l}\text { Digital triage: Novel strategies for population health management in } \\
\text { response to the COVID-19 Pandemic }\end{array}$ & Healthcare/Medical data & $\mathrm{AI} / \mathrm{ML} / \mathrm{DL} / \mathrm{DM}$ & Healthcare \\
\hline $\begin{array}{l}\text { Efficacy of a Student-Led Community Contact Tracing Program } \\
\text { Partnered with an Academic Medical Center during the COVID-19 } \\
\text { Pandemic. }\end{array}$ & Healthcare/Medical data & $\begin{array}{l}\text { Tools, platforms, } \\
\text { Mobile and web app }\end{array}$ & Healthcare \\
\hline $\begin{array}{l}\text { eHealth Literacy of German Physicians in the Pre-COVID-19 Era: } \\
\text { Questionnaire Study. }\end{array}$ & & $\begin{array}{l}\text { Tools, platforms, } \\
\text { Mobile and web app }\end{array}$ & \\
\hline $\begin{array}{l}\text { Epidemiological Determinants of Acute Respiratory Syndrome } \\
\text { Coronavirus-2 Disease Pandemic and The Role of the Bacille- } \\
\text { Calmette-Guerin Vaccine in Reducing Morbidity and Mortality }\end{array}$ & Open datasets & & \\
\hline $\begin{array}{l}\text { Evaluating How Smartphone Contact Tracing Technology Can } \\
\text { Reduce the Spread of Infectious Diseases: The Case of COVID-19 }\end{array}$ & Contact tracing data & $\begin{array}{l}\text { Tools, platforms, } \\
\text { Mobile and web app }\end{array}$ & \\
\hline $\begin{array}{l}\text { Exploring Speech Cues in Web-Mined COVID-19 Conversational } \\
\text { Vlogs }\end{array}$ & Social/News media data & Analytics & Government \\
\hline $\begin{array}{l}\text { Factors Affecting Infection Control Behaviors to Prevent COVID-19: } \\
\text { An Online Survey of Nursing Students in Anhui, China in March and } \\
\text { April } 2020 \text {. }\end{array}$ & Survey data & Analytics & Researchers \\
\hline $\begin{array}{l}\text { Factors associated with preventive behaviors, anxiety among } \\
\text { Healthcare workers and response preparedness against COVID-19 } \\
\text { outbreak: A one health approach }\end{array}$ & Survey data & Analytics & Government \\
\hline $\begin{array}{l}\text { Factors associated with self-perceived knowledge of COVID-19: a } \\
\text { study among women from the NINFEA birth cohort. }\end{array}$ & Survey data & $\begin{array}{l}\text { Tools, platforms, } \\
\text { Mobile and web app }\end{array}$ & Researchers \\
\hline $\begin{array}{l}\text { Fake News and COVID-19 in Italy: Results of a Quantitative } \\
\text { Observational Study. }\end{array}$ & Contact tracing data & $\begin{array}{l}\text { Tools, platforms, } \\
\text { Mobile and web app }\end{array}$ & Researchers \\
\hline Fighting infodemic: Need for robust health journalism in India & Social/News media data & $\begin{array}{l}\text { Tools, platforms, } \\
\text { Mobile and web app }\end{array}$ & Researchers \\
\hline $\begin{array}{l}\text { Findings of a Cross-Sectional Survey on Knowledge, Attitudes, and } \\
\text { Practices about COVID-19 in Uganda: Implications for Public Health } \\
\text { Prevention and Control Measures }\end{array}$ & Survey data & Analytics & \\
\hline $\begin{array}{l}\text { Forecasting for a data-driven policy using time series methods in } \\
\text { handling COVID-19 Pandemic in Jakarta }\end{array}$ & Healthcare/Medical data & Analytics & Government \\
\hline $\begin{array}{l}\text { Framework for Managing the COVID-19 Infodemic: Methods and } \\
\text { Results of an Online, Crowdsourced WHO Technical Consultation. }\end{array}$ & & $\begin{array}{l}\text { Tools, platforms, } \\
\text { Mobile and web app }\end{array}$ & \\
\hline $\begin{array}{l}\text { Gaps in Knowledge About COVID-19 Among US Residents Early in } \\
\text { the Outbreak }\end{array}$ & Survey data & Analytics & Researchers \\
\hline $\begin{array}{l}\text { GeoCoV19: A Dataset of Hundreds of Millions of Multilingual } \\
\text { COVID-19 Tweets with Location Information }\end{array}$ & Social/News media data & $\begin{array}{l}\text { Tools, platforms, } \\
\text { Mobile and web app }\end{array}$ & Researchers \\
\hline
\end{tabular}




\title{
Issues in Information Systems
}

\author{
Volume 22, Issue 4, pp. 178-192, 2021
}

Health Literacy and Preventive Behaviors Modify the Association between Pre-Existing Health Conditions and Suspected COVID-19 Symptoms: A Multi-Institutional Survey.

Healthcare professionals' acts of correcting health misinformation on social media

Hi-COVIDNet: Deep Learning Approach to Predict Inbound COVID19 Patients and Case Study in South Korea

Influenza vaccination among U.S. pediatric patients receiving care from federally funded health centers

Information technology solutions, challenges, and suggestions for tackling the COVID-19 Pandemic

Knowledge and Behaviors of Adults with Underlying Health Conditions During the Onset of the COVID-19 U.S. Outbreak: The Chicago COVID-19 Comorbidities Survey.

Knowledge level and factors influencing prevention of COVID-19

Pandemic among residents of Dessie and Kombolcha City

administrations, North-East Ethiopia: a population-based cross-

sectional study.

Knowledge, attitudes and practices related to the COVID-19 outbreak among Romanian adults with cancer: a cross-sectional national survey

Leaving no stone unturned in light of the COVID-19 faecal-oral hypothesis? A water, sanitation and hygiene (WASH) perspective targeting low-income countries

Leveraging epidemiological principles to evaluate Sweden's COVID19 response

Link Analysis to Discover Insights from Structured and Unstructured Data on COVID-19

Lockdowns \&amp; Rebounds: A Data Analysis of What Happens

Next

Management of psychiatric conditions and delirium during the

COVID-19 Pandemic across continents: lessons learned and recommendations

Mapping County-Level Mobility Pattern Changes in the United States in Response to COVID-19

Mapping of Health Literacy and Social Panic Via Web Search Data During the COVID-19 Public Health Emergency: Infodemiological Study.

MAS-SEIR-II Simulation on COVID-19 in China

Medical Transdisciplinary Cluster Development for Multivariable COVID-19 Epidemiological Situation Modeling

Mental health outcomes associated with the COVID-19 Pandemic:

Prevalence and risk factors in a southern US state

Mixed-Mode Pandemic Modeling

Mobile Fotonovelas Within a Text Message Outreach: An Innovative Tool to Build Health Literacy and Influence Behaviors in Response to the COVID-19 Pandemic.

Modeling Epidemic Spread with Spike-Based Models

MorPOP: A Fast and Granular Agent-Based Model of COVID-19 to

Examine School Mitigation Strategies in Newfoundland \&amp;

Labrador

Nowhere to hide: The significant impact of coronavirus disease 2019

(COVID-19) measures on elite and semi-elite South African athletes

On the use of clinical based infection data for Pandemic case studies

\begin{tabular}{|c|c|c|}
\hline Healthcare/Medical data & $\begin{array}{l}\text { Tools, platforms, } \\
\text { Mobile and web app }\end{array}$ & Healthcare \\
\hline Survey data & Analytics & Researchers \\
\hline Contact tracing data & Analytics & Healthcare \\
\hline Healthcare/Medical data & $\mathrm{AI} / \mathrm{ML} / \mathrm{DL} / \mathrm{DM}$ & Healthcare \\
\hline Healthcare/Medical data & Experiment/observation & Researchers \\
\hline Healthcare/Medical data & $\mathrm{AI} / \mathrm{ML} / \mathrm{DL} / \mathrm{DM}$ & Healthcare \\
\hline Open datasets & Experiment/observation & Public \\
\hline Healthcare/Medical data & Experiment/observation & Healthcare \\
\hline Healthcare/Medical data & $\mathrm{AI} / \mathrm{ML} / \mathrm{DL} / \mathrm{DM}$ & Researchers \\
\hline Healthcare/Medical data & Analytics & Researchers \\
\hline Healthcare/Medical data & $\mathrm{AI} / \mathrm{ML} / \mathrm{DL} / \mathrm{DM}$ & Healthcare \\
\hline Open datasets & Experiment/observation & Public \\
\hline Healthcare/Medical data & $\mathrm{AI} / \mathrm{ML} / \mathrm{DL} / \mathrm{DM}$ & Healthcare \\
\hline Open datasets & Experiment/observation & Public \\
\hline Healthcare/Medical data & Experiment/observation & Researchers \\
\hline Healthcare/Medical data & Experiment/observation & Healthcare \\
\hline Healthcare/Medical data & Experiment/observation & Researchers \\
\hline Healthcare/Medical data & Experiment/observation & Healthcare \\
\hline Healthcare/Medical data & Experiment/observation & Healthcare \\
\hline Healthcare/Medical data & Experiment/observation & Healthcare \\
\hline Healthcare/Medical data & Analytics & Healthcare \\
\hline Healthcare/Medical data & Experiment/observation & Healthcare \\
\hline Healthcare/Medical data & Experiment/observation & Healthcare \\
\hline Healthcare/Medical data & Experiment/observation & Healthcare \\
\hline
\end{tabular}




\title{
Issues in Information Systems
}

\author{
Volume 22, Issue 4, pp. 178-192, 2021
}

\begin{tabular}{|c|c|c|c|}
\hline $\begin{array}{l}\text { Open government data, uncertainty and coronavirus: An } \\
\text { infodemiological case study }\end{array}$ & Healthcare/Medical data & Experiment/observation & Healthcare \\
\hline $\begin{array}{l}\text { Optimisation of Non-Pharmaceutical Measures in COVID-19 Growth } \\
\text { via Neural Networks }\end{array}$ & Open datasets & Experiment/observation & Healthcare \\
\hline $\begin{array}{l}\text { Pandemic Pulse: Unraveling and Modeling Social Signals During the } \\
\text { COVID-19 Pandemic }\end{array}$ & Open datasets & Experiment/observation & Researchers \\
\hline $\begin{array}{l}\text { Pediatric Neurology Research in the Twenty-First Century: Status, } \\
\text { Challenges, and Future Directions Post-COVID-19 }\end{array}$ & Healthcare/Medical data & Experiment/observation & Healthcare \\
\hline $\begin{array}{l}\text { PocketCare: Tracking the Flu with Mobile Phones Using Partial } \\
\text { Observations of Proximity and Symptoms }\end{array}$ & Healthcare/Medical data & $\begin{array}{l}\text { Tools, platforms, } \\
\text { Mobile and web app }\end{array}$ & Healthcare \\
\hline Polio in Afghanistan: The Current Situation amid COVID-19. & Healthcare/Medical data & Experiment/observation & Healthcare \\
\hline $\begin{array}{l}\text { Population risk factors for COVID-19 deaths in Nigeria at sub- } \\
\text { national level. }\end{array}$ & Healthcare/Medical data & Experiment/observation & Healthcare \\
\hline $\begin{array}{l}\text { Positive and negative affect of university and college students during } \\
\text { COVID-19 outbreak: a network-based survey. }\end{array}$ & Open datasets & Experiment/observation & Researchers \\
\hline Predicting COVID-19 Evolution during Mid-March Crisis & Healthcare/Medical data & & Healthcare \\
\hline $\begin{array}{l}\text { Preempt: Scalable Epidemic Interventions Using Submodular } \\
\text { Optimization on Multi-GPU Systems }\end{array}$ & Healthcare/Medical data & $\mathrm{AI} / \mathrm{ML} / \mathrm{DL} / \mathrm{DM}$ & Healthcare \\
\hline $\begin{array}{l}\text { Preventing COVID-19 and Its Sequela: "There Is No Magic Bullet. } \\
\text { It's Just Behaviors" }\end{array}$ & Open datasets & Experiment/observation & Healthcare \\
\hline $\begin{array}{l}\text { Privacy-Preserving Contact Tracing Using Homomorphic Encryption: } \\
\text { Poster Abstract }\end{array}$ & Healthcare/Medical data & $\begin{array}{l}\text { Tools, platforms, } \\
\text { Mobile and web app }\end{array}$ & Healthcare \\
\hline $\begin{array}{l}\text { Problematic internet use among young and adult population in } \\
\text { Bangladesh: Correlates with lifestyle and online activities during the } \\
\text { COVID-19 Pandemic }\end{array}$ & Open datasets & Experiment/observation & Researchers \\
\hline $\begin{array}{l}\text { Proctologic emergency consultation during COVID-19: Comparative } \\
\text { cross-sectional cohort study }\end{array}$ & Healthcare/Medical data & Experiment/observation & Healthcare \\
\hline $\begin{array}{l}\text { Protocol for a national probability survey using home specimen } \\
\text { collection methods to assess prevalence and incidence of SARS-CoV- } \\
2 \text { infection and antibody response }\end{array}$ & Healthcare/Medical data & Experiment/observation & Healthcare \\
\hline $\begin{array}{l}\text { Psychosocial factors and hospitalisations for COVID-19: Prospective } \\
\text { cohort study based on a community sample. }\end{array}$ & Survey data & Experiment/observation & Researchers \\
\hline $\begin{array}{l}\text { Public health preparedness and responses to the coronavirus disease } \\
2019 \text { (COVID-19) Pandemic in South Asia: a situation and policy } \\
\text { analysis }\end{array}$ & Open datasets & Experiment/observation & Researchers \\
\hline $\begin{array}{l}\text { Rapid Detection of COVID-19 Clusters in the United States Using a } \\
\text { Prospective Space-Time Scan Statistic: An Update }\end{array}$ & Healthcare/Medical data & Experiment/observation & Healthcare \\
\hline $\begin{array}{l}\text { Readability of online COVID-19 health information: a comparison } \\
\text { between four English speaking countries. }\end{array}$ & Healthcare/Medical data & Experiment/observation & Healthcare \\
\hline $\begin{array}{l}\text { Readability of online patient education material for the novel } \\
\text { coronavirus disease (COVID-19): a cross-sectional health literacy } \\
\text { study. }\end{array}$ & Healthcare/Medical data & Experiment/observation & Healthcare \\
\hline $\begin{array}{l}\text { Readability, content, and quality of COVID-19 patient education } \\
\text { materials from academic medical centers in the United States }\end{array}$ & Open datasets & Experiment/observation & Researchers \\
\hline Reconstructing the MERS Disease Outbreak from News & Open datasets & Experiment/observation & Researchers \\
\hline $\begin{array}{l}\text { ReCOVery: A Multimodal Repository for COVID-19 News } \\
\text { Credibility Research }\end{array}$ & Open datasets & Experiment/observation & Researchers \\
\hline $\begin{array}{l}\text { Reflecting on prediction strategies for epidemics: Preparedness and } \\
\text { public health response }\end{array}$ & Open datasets & Experiment/observation & Researchers \\
\hline $\begin{array}{l}\text { Research on Prediction of Infectious Diseases, Their Spread via Social } \\
\text { Media and Their Link to Education }\end{array}$ & Open datasets & Experiment/observation & Researchers \\
\hline $\begin{array}{l}\text { Responsible, Automated Data Gathering for Timely Citizen } \\
\text { Dashboard Provision During a Global Pandemic (COVID-19) }\end{array}$ & Contact tracing data & $\mathrm{AI} / \mathrm{ML} / \mathrm{DL} / \mathrm{DM}$ & Healthcare \\
\hline
\end{tabular}




\title{
Issues in Information Systems
}

\author{
Volume 22, Issue 4, pp. 178-192, 2021
}

Risk assessment and seroprevalence of SARS-CoV-2 infection in Healthcare workers of COVID-19 and non-COVID-19 hospitals in Southern Switzerland

Safety-Critical Control of Compartmental Epidemiological Models With Measurement Delays

SARS-CoV-2 controlled human infection models: Ethics, challenge agent production and regulatory issues

Sense of coherence mediates the relationship between digital health literacy and anxiety about the future in aging population during the COVID-19 Pandemic: a path analysis.

Simulating COVID-19 Containment Measures Using the South Korean Patient Data: Poster Abstract

Simulating the Impact of Hospital Capacity and Social Isolation to Minimize the Propagation of Infectious Diseases

Social media can have an impact on how we manage and investigate the COVID-19 Pandemic

Social Media Use, eHealth Literacy, Disease Knowledge, and Preventive Behaviors in the COVID-19 Pandemic: Cross-Sectional Study on Chinese Netizens.

Socio-economic inequality in global incidence and mortality rates from coronavirus disease 2019: an ecological study

Statement on Mental Health and the Coronavirus Pandemic

Stressful life events and social capital during the early phase of COVID-19 in the U.S.

Subgroup Analysis of an Epidemic Response Network of

Organizations: 2015 MERS Outbreak in Korea

Successful Models of Hackathons and Innovation Contests to Crowdsource Rapid Responses to COVID-19

Summarize the Etiology and Epidemiology Characteristics of the New Coronavirus

TDEFSI: Theory-Guided Deep Learning-Based Epidemic Forecasting with Synthetic Information

Teaching psychomotor skills online: exploring the implications of novel coronavirus on health professions education.

Telemedicine in cardiovascular surgery during COVID-19 Pandemic:

A systematic review and our experience.

Telemedicine Usage Among Urologists During the COVID-19

Pandemic: Cross-Sectional Study.

Temporal Pattern of Retweet(s) Help to Maximize Information Diffusion in Twitter

The Australian Institute of Sport framework for rebooting sport in a COVID-19 environment

The Best Tech for Contact Tracing? Systems Designed for Healthcare Workers

The COVID-19 'infodemic': a new front for information professionals.

The COVID-19 Pandemic in Greece, Iceland, New Zealand, and Singapore: Health policies and lessons learned

The impact of "flattening the curve" on Generation Z

The impact of COVID-19 Pandemic on mental health \& wellbeing among home-quarantined Bangladeshi students: A cross-sectional pilot study

Typical Patterns of Government Response Measures and Trends for COVID-19 Pandemic

\begin{tabular}{|c|c|c|}
\hline Healthcare/Medical data & Experiment/observation & Healthcare \\
\hline Healthcare/Medical data & Experiment/observation & Healthcare \\
\hline Healthcare/Medical data & Experiment/observation & Healthcare \\
\hline Open datasets & Experiment/observation & Researchers \\
\hline Healthcare/Medical data & Experiment/observation & Healthcare \\
\hline Healthcare/Medical data & Experiment/observation & Healthcare \\
\hline Healthcare/Medical data & Experiment/observation & Healthcare \\
\hline Survey data & Experiment/observation & Researchers \\
\hline Survey data & Experiment/observation & Researchers \\
\hline Healthcare/Medical data & Experiment/observation & Healthcare \\
\hline Open datasets & Experiment/observation & Researchers \\
\hline Open datasets & Experiment/observation & Researchers \\
\hline Healthcare/Medical data & Experiment/observation & Healthcare \\
\hline Healthcare/Medical data & Experiment/observation & Researchers \\
\hline Open datasets & Experiment/observation & Researchers \\
\hline Healthcare/Medical data & Experiment/observation & Healthcare \\
\hline Healthcare/Medical data & $\begin{array}{l}\text { Tools, platforms, } \\
\text { Mobile and web app }\end{array}$ & Healthcare \\
\hline Healthcare/Medical data & $\begin{array}{l}\text { Tools, platforms, } \\
\text { Mobile and web app }\end{array}$ & Healthcare \\
\hline Healthcare/Medical data & $\mathrm{AI} / \mathrm{ML} / \mathrm{DL} / \mathrm{DM}$ & Healthcare \\
\hline Healthcare/Medical data & Experiment/observation & Healthcare \\
\hline Healthcare/Medical data & $\begin{array}{l}\text { Tools, platforms, } \\
\text { Mobile and web app }\end{array}$ & Healthcare \\
\hline Healthcare/Medical data & Experiment/observation & Healthcare \\
\hline Survey data & Experiment/observation & Healthcare \\
\hline Open datasets & Experiment/observation & Researchers \\
\hline Survey data & Analytics & Healthcare \\
\hline Survey data & Analytics & Government \\
\hline
\end{tabular}

